\title{
Kidney Injury Molecule-1 Measurement
}

National Cancer Institute

\section{Source}

National Cancer Institute. Kidney Injury Molecule-1 Measurement. NCI Thesaurus. Code C100433.

The determination of the amount of kidney injury molecule-1 present in a sample. 